\title{
Knowledge of obstetric danger signs and associated factors: a study among mothers in Shashamane town, Oromia region, Ethiopia
}

Biresaw Wassihun ${ }^{1 *}$, Berhanu Negese ${ }^{1}$, Hunduman Bedada ${ }^{1}$, Solomon Bekele ${ }^{1}$, Agegnehu Bante ${ }^{1}$, Tomas Yeheyis$^{1}$, Agere Abebe ${ }^{1}$, Duro uli ${ }^{1}$, Merima Mohammed ${ }^{1}$, Salasebish Gashawbez ${ }^{1}$ and Emebet Hussen ${ }^{2}$

\begin{abstract}
Background: Child birth which is a special moment for parents, families and communities is also a time of intense vulnerability. In many developing countries including Ethiopia, maternal morbidity and mortality still pose a substantial burden. Raising awareness of women about the danger signs of pregnancy and childbirth is the first essential step in appropriate and timely obstetric care.

Objective: To assess the knowledge of obstetric danger signs among mothers and associated factors in Shashamane town, oromia region, Ethiopia.

Methods: A community based cross sectional study design was employed. All kebeles were included in study; the number of households was determined using proportionate-to-population size then systematic random sampling technique to select 422 women who gave birth in Shashamane town between April and May 2018. A structured questionnaire was used to collect data. Data was checked and entered into Epi data version 3.1 then exported to Statistical Package for Social Science version 23 for analysis. Univariate, bivariate and multivariable analysis with 95\% $\mathrm{Cl}$ was carried out. Women who spontaneously mentioned at least two danger signs of pregnancy from eight items were considered to have good knowledge of the obstetric danger signs.
\end{abstract}

Result: A total of 422 mothers were involved in the study. The mean age of the respondent was 25 with a standard deviation of 4.3 year. $59.5 \%$ of the respondents were found to have poor knowledge of obstetric danger signs. Majority of respondents mentioned vaginal bleeding (64.7\%) as a danger sign of pregnancy. According to the result of the multivariable analysis, antenatal care was significantly associated with the knowledge of obstetric danger sign. Respondents who attended antenatal care were 1.26 times more likely to have good knowledge of obstetric danger signs than those who had no antenatal care $[\mathrm{AOR}=1.26,95 \% \mathrm{Cl}(1.08-1.85)]$. Respondents who gave birth at health center were 3.57 time more likely to have good knowledge of obstetric danger signs than those who gave birth at home $[A O R=3.57,95 \% \mathrm{Cl}(1.23-10.39)]$.

Conclusion: According to this study, the knowledge of obstetric danger signs was poor. Some of the factors associated with this knowledge were antenatal care attendance and place of delivery; therefore, it is recommended that mothers should have at least four antenatal visits; this may create good relationship with the providers and enhance their knowledge. In addition to this providing compassionate and respectful maternity care in health facility is also crucial steps to attract more women to health facilities, and to reduce home deliveries.

Keywords: Knowledge, Obstetric, Danger sign, Ethiopia

\footnotetext{
*Correspondence: bireswas@gmail.com

${ }^{1}$ Colleges of Medicine and Health Sciences, Arba Minch University, Arba

Minch, Ethiopia

Full list of author information is available at the end of the article
}

(c) The Author(s). 2020 Open Access This article is distributed under the terms of the Creative Commons Attribution 4.0 International License (http://creativecommons.org/licenses/by/4.0/), which permits unrestricted use, distribution, and reproduction in any medium, provided you give appropriate credit to the original author(s) and the source, provide a link to the Creative Commons license, and indicate if changes were made. The Creative Commons Public Domain Dedication waiver (http://creativecommons.org/publicdomain/zero/1.0/) applies to the data made available in this article, unless otherwise stated. 


\section{Plain English summary}

Worldwide, a projected half million women die as a result of pregnancy and childbirth related complications. In Ethiopia, only one-third of mothers gives birth at a health institution and the maternal mortality ratio is $410 / 100,000$ live births. One of the contributing factors to maternal deaths was a lack of knowledge of pregnancy-related danger signs. Therefore, this study aimed to investigate the knowledge of obstetric danger signs among recently-delivered women and associated factors in Shashamane town, oromia region, Ethiopia. A community based cross-sectional study design was employed on 422 mothers who gave birth in Shashamane town between April and May 2018. The data was collected using a face to face interview and questionnaire. A total of 422 women responded fully for the questions asked. The result of the response was analyzed using statistical software to identify which variables were associated with knowledge of obstetric danger signs. Women attending antenatal care, and giving birth in health facility had better knowledge of obstetric danger sign.

\section{Background}

The burden of pregnancy complications is higher in developing countries [1]. In 2015, a total of 303,000 women have lost their life due to easily preventable pregnancy and childbirth related complications, 99\% of which were contributed by low income countries [2]. Knowledge of danger signs during pregnancy, labour and delivery is crucial for safe motherhood [3]. Pregnancy danger signs are those symptoms that may signal danger to a pregnant woman or her fetus and therefore require immediate medical attention. The most common danger signs during pregnancy are severe vaginal bleeding, swollen face/hand, and blurred vision: danger signs during labor and childbirth include severe vaginal bleeding, prolonged labor, and convulsions; Danger signs during the postpartum period include severe bleeding following childbirth, loss of consciousness after childbirth, and fever [4]. Many of the complications that result in maternal deaths contributing to prenatal deaths are unpredictable, and their onset can be both sudden and severe $[5,6]$. In low income countries maternal mortality due to childbirth related complication could be prevented if pregnant women recognize danger signs and seek immediate obstetric care [7]. Poor knowledge of danger sign is one of the most common causes of failure to recognize the complication when it occurs and delaying the decision to seek care [8]. The national reproductive strategy of Ethiopia has emphasis on maternal and newborn health to reduce high maternal and neonatal death [8]. The strategy focuses on the need to empower women, men, families and communities to recognize pregnancy related risks, and to take responsibility for developing and implementing appropriate response to them [9]. In many low resources countries, home delivery is prevalent. Therefore, it is important that people are trained to recognize danger signs and develop plans for emergencies [9]. Maternal deaths during child birth has profoundly bad consequences for her family, particularly for children left without care taker and have a negative impact on the society and economies of their nations at large [10]. Majority of maternal deaths are avoidable, if women with complications are able to identify and seek appropriate emergency obstetric care [9]. Maternal deaths have both direct and indirect causes. Around $85 \%$ of maternal deaths worldwide are due to direct obstetric complications such as severe postpartum bleeding, infections after delivery, unsafe induced abortion, hypertensive disorders in pregnancy and obstructed labour [11]. Direct cause of maternal mortality was easily avoidable if the mother and family recognize sign and seeking immediate care, health facility provides quality care and transportation were easily available [12]. High levels of maternal mortality can be reduced by providing quality maternity service and empowering women with knowledge of the danger signs of pregnancy and promote appropriate health seeking perceptions. In Ethiopia; however, few studies have been conducted with regarding the knowledge of obstetric danger sign during pregnancy, childbirth and associated factors and we could not find any published research that is conducted in this study area. This study was therefore, aimed at assessing the current status of knowledge of obstetric danger signs and associated factors among mothers in Shashamane town, oromia region, Ethiopia.

\section{Methods \\ Study area}

The study was conducted in Shashamane town, located in central part of Oromia region, $130 \mathrm{~km}$ from Adama, the capital city of the region and $248 \mathrm{~km}$ from Addis Ababa, the capital city of Ethiopia. The town was established in 1903 e. c. Based on the 2007 Census the town has a total population of 218,335 where, about $48.9 \%$ are females. It consists of peoples with different languages, more than 18 ethnic groups and foreigners like the Ras Teferian community. There are 74 health institutions in the town. Among this there are two public hospitals which serve the district and referral levels 30 pharmacies six health centers, 28 private clinics, one private hospital and five health posts.

\section{Study design and period}

A community based cross sectional study was conducted in Shashamane town between April and May 2018. 


\section{Population}

\section{Source population}

All mothers who gave birth in the last 1 year at Shashamane town.

\section{Study population}

All mothers who gave birth within the last 1 year from selected four kebeles of Shashamane town and fulfill inclusion criteria.

\section{Inclusion criteria}

All mothers who gave birth in the last year in Shashamane town.

Women who were resident of the area for the past 6 months.

\section{Exclusion criteria}

Mothers who were critically ill and unable to communicate at the time of data collection.

\section{Sample size determination}

The single population proportion formula was used to calculate the sample size by hypothesizing that the proportion of mothers who had good knowledge of danger sign would be $50 \%$, adding a non-response rate of $10 \%$, and using the assumptions of a 95\% confidence level and a 5\% margin of error. The resulting sample size was 422 mothers.

\section{Sampling procedure}

Systematic random sampling was used to select study participant from 10 kebeles of Shashamane town administration. All kebeles were included in the study and the number of households was determined using proportionate-to-population size.

To select the first household the data collectors used the kebeles administration office and church as a starting point. The data collectors used spinning techniques to select the first house hold by rotating a pen and select the house which is found to the direction of the pen. Then went to the right direction of the first household. From this onwards data was collected in every 12th interval until the desired sample was achieved in each kebeles.

A mother in the selected household was interviewed. For household with more than one individual, only one person was selected using a lottery. For those selected household which was unavailable during data collection, data collectors revisited three times at different time intervals, and if interviewers still failed to get an individual in the house hold, it was considered as non-response.

\section{Data collection tool and procedure}

Data were collected by face to face interview using a structured questionnaire adapted from the survey tools developed by JHPIEGO's Maternal Neonatal Health Program. The questionnaire was used to assess the knowledge of mothers regarding the pregnancy danger signs. The data collection tool was pre-tested on women with similar characteristics living out of the study area on $10 \%$ of sample size. After pre-testing further adjustments to the data collection tool were made to improve clarity. All of the questionnaires were checked for completeness and accuracy before, during and after the period of data collection. Five diploma midwives who were fluent in the local language were involved in the data collection. Two Bachelor of Science degree (BSc) holder health professionals were recruited as supervisors.

\section{Data quality control}

After pre-testing the questionnaire, Chronbach Alpha was calculated by using SPSS window version 23.0 to test internal consistency (reliability) of the item and Chronbach Alpha greater than 0.7 was considered as reliable. On the top of this, content validity was cross checked by another maternal and reproductive health expert at Arba Minch University. Data collectors and supervisors were trained for 2 days on the study instrument and data collection procedure. The principal investigator and the supervisors checked the data for completeness and corrective measures was taken accordingly.

\section{Data processing and analysis}

The collected data were checked manually for completion and any incomplete or misfiled questions, cleaned and stored for consistency, entered into EpiData version 3.1 (EpiData Association, Odense, Denmark), and then exported to SPSS version 23.0 (IBM Corp., Armonk, NY, USA) for analysis. Descriptive statistics were calculated and presented using tables and figures. Multivariable logistic regression analysis was performed to adjust for possible confounding variables. Variables that were significant in the bivariate logistic regression were entered into the multiple regression analysis. The $p<0.05$ or $95 \%$ confidence intervals (CIs) not including 1.0 were considered to indicate statistical significance.

\section{Measurement}

Danger signs are indications of potential obstetric complications. Knowledge of women about obstetric danger signs were measured by the total number of correct spontaneous answers to eight items on knowledge of pregnancy danger signs and eight items on knowledge of labor and childbirth danger signs with a minimum score 
of zero and maximum of eight. Spontaneous knowledge refers to the respondent's naming a sign without being asked about that sign by name. Only true obstetric complications spontaneously mentioned by individual respondents were included. Accordingly, two categories were developed for each pregnancy and childbirth danger signs. Good knowledge about pregnancy danger signs: women who spontaneously mentioned at least two danger signs of pregnancy. Poor knowledge about pregnancy danger signs: women who did not spontaneously mention two danger signs of pregnancy. Good knowledge about the danger signs of labor and childbirth: women who spontaneously mentioned at least two danger signs of labor and childbirth. Poor knowledge about the danger signs of labor and delivery: women who did not spontaneously mention two danger signs of labor and childbirth.

\section{Result}

Socio demographic characteristics

A total of 422 mothers were involved in the study. The mean age of respondents was 25 with a standard deviation of 4.3 years. The minimum and maximum age of respondent was 16 and 39 respectively. Around 154 (36.5\%) of the participants were Muslim and 266 (63\%) were Oromo in ethnicity. Majority 394 (93.4\%) of the women were married and majority $275(65.2 \%)$ of the respondents were housewives. 162 (38.4\%) had completed primary school and $57(13.5 \%)$ had completed college or greater. Majority $243(57.6 \%)$ of the respondents had a monthly family income $<4000$ Ethiopian birr (Table 1).

\section{Obstetric history related characteristics}

Out of 422 respondents, 244 (57.8\%) were multi para while other 164 (38.9\%) were grand multi para. Majority of the respondents, $368(87.2 \%)$ gave birth at a health center. From the total respondents, $334(79.5 \%)$ had a spontaneous vaginal delivery, while $86(20.4 \%)$ had an instrumental delivery. Almost all 323 (76.5\%) of the respondents decided where they gave birth by themselves and $86(20.4 \%)$ respondents had the decision made by their husband, only 13 (3.1\%) were decided by their relatives (Table 2).

\section{Knowledge about obstetric danger signs}

Knowledge of obstetric complications was assessed by questions of danger signs related to pregnancy and childbirth. The most commonly mentioned danger sign of pregnancy was vaginal bleeding (64.7\%), followed by absent or decreased fetal movements (38.6\%). Similarly, the most commonly mentioned danger sign during childbirth was bleeding (60\%), followed by absent or
Table 1 Socio demographic characteristics of mother in Shashamane town, April, 2018

\begin{tabular}{|c|c|c|}
\hline Variable & Frequency $(n=422)$ & Percent (\%) \\
\hline \multicolumn{3}{|l|}{ Age in year } \\
\hline $16-19$ & 19 & 4.5 \\
\hline $20-24$ & 164 & 38.9 \\
\hline $25-29$ & 163 & 38.8 \\
\hline 30 and above & 76 & 18.0 \\
\hline \multicolumn{3}{|l|}{ Marital status } \\
\hline Single & 16 & 3.8 \\
\hline Married & 394 & 93.4 \\
\hline Divorced & 11 & 2.6 \\
\hline Widowed & 1 & 0.2 \\
\hline \multicolumn{3}{|l|}{ Ethnicity } \\
\hline Oromo & 266 & 63 \\
\hline Amara & 62 & 14.5 \\
\hline Wolayita & 39 & 9.2 \\
\hline Sidama & 16 & 3.8 \\
\hline Tigre & 13 & 3.1 \\
\hline Other ${ }^{a}$ & 27 & 6.4 \\
\hline \multicolumn{3}{|l|}{ Religion } \\
\hline Muslim & 154 & 36.5 \\
\hline Orthodox & 139 & 32.9 \\
\hline Protestant & 124 & 29.4 \\
\hline Catholic & 5 & 1.2 \\
\hline \multicolumn{3}{|l|}{ Occupation } \\
\hline Unemployed & 275 & 65.2 \\
\hline Employer & 43 & 10.2 \\
\hline Merchant & 60 & 14.2 \\
\hline Private employer & 26 & 6.2 \\
\hline Farmer & 1 & 0.2 \\
\hline Others $^{b}$ & 17 & 4 \\
\hline \multicolumn{3}{|l|}{ Educational status } \\
\hline No formal education & 69 & 16.4 \\
\hline Primary school & 162 & 38.4 \\
\hline Secondary and preparatory & 134 & 31.8 \\
\hline Collage and above & 57 & 13.5 \\
\hline \multicolumn{3}{|l|}{ Monthly income } \\
\hline Below 4000 & 243 & 57.6 \\
\hline Above 4000 & 179 & 42.4 \\
\hline Median 4000 & & \\
\hline
\end{tabular}

decrease fetal movements (28.4\%). In addition, a commonly mentioned danger sign during post-partum was postnatal bleeding (63.3\%), followed by postnatal fever. $251(59.5 \%)$ of the respondents were found to have poor 
Table 2 Obstetric characteristics of mothers in Shashamane town, April, 2018

\begin{tabular}{|c|c|c|}
\hline Variables & Frequency $(n=422)$ & Percent (\%) \\
\hline \multicolumn{3}{|c|}{ Age of first pregnancy in year } \\
\hline$<20$ & 134 & 31.8 \\
\hline $20-24$ & 275 & 65.2 \\
\hline $25-29$ & 12 & 2.8 \\
\hline $30-34$ & 1 & 0.2 \\
\hline \multicolumn{3}{|c|}{ Total number of pregnancy } \\
\hline 1 & 178 & 42.2 \\
\hline $2-5$ & 209 & 49.5 \\
\hline$>6$ & 35 & 8.9 \\
\hline \multicolumn{3}{|c|}{ Pregnancy resulted alive } \\
\hline 0 & 18 & 4.3 \\
\hline 1 & 193 & 45.7 \\
\hline$>1$ & 211 & 50 \\
\hline \multicolumn{3}{|c|}{ Total number of children } \\
\hline 1 & 14 & 3.3 \\
\hline $2-4$ & 376 & 89.1 \\
\hline$>5$ & 32 & 7.6 \\
\hline \multicolumn{3}{|l|}{ ANC follow up } \\
\hline Yes & 367 & 87.0 \\
\hline No & 55 & 13.0 \\
\hline \multicolumn{3}{|c|}{ Number of ANC follow up } \\
\hline One & 5 & 1.3 \\
\hline Two & 22 & 5.9 \\
\hline Three & 107 & 29.1 \\
\hline Four and above & 233 & 63.4 \\
\hline
\end{tabular}

Key: ANC Antenatal care

knowledge; however, 171(40.5\%) had good knowledge of obstetric danger sign (Table 3), (Fig. 1).

\section{Factors affecting knowledge of obstetric danger signs}

According to the bivariate analysis, knowledge was significantly associated with educational status of mothers. Respondents who had a formal education were 6.01 times more likely to have good knowledge of obstetric danger signs than respondents did not have formal education $[\mathrm{COR}=6.01(95 \% \mathrm{CI} 2.26-2.60)]$. Place of delivery was significantly associated with knowledge of obstetrics danger signs, respondents who gave birth at a health institution were 5.7 times more likely to have good knowledge of obstetric danger signs than those who gave birth at home $[\mathrm{COR}=5.7(95 \% \mathrm{CI} 2.98-11.17)]$. Occupation of respondent was also significantly associated with knowledge of obstetric danger signs. Respondents who were working for a governmental employer were 1.36 times more likely to have good knowledge of obstetric danger signs than housewives $[\mathrm{COR}=1.36 \quad(95 \% \mathrm{CI}$ 1.853-2.17)]. In multivariate logistic regression on both socio-demographic and obstetric history of respondents, number of antenatal care (ANC) visits and place of delivery were found to be significantly associated with knowledge of obstetric danger signs at $P$-value of $<0.05$. Respondents who attended ANC were 1.26 times more likely to have good knowledge of obstetric danger signs than respondent with no ANC $[\mathrm{AOR}=1.26(95 \% \mathrm{CI}$ $1.07-2.85)]$. Respondents who gave birth in the health center had 3.57 time more likely to have good knowledge of obstetric danger signs than those respondents who gave birth at home $[\mathrm{AOR}=3.57$ (95\%CI1.2310.39)] (Table 4).

\section{Discussion}

The findings of this study revealed that the good knowledge of respondents regarding obstetric danger sign was $40 \%$ which is higher than other studies conducted in Egypt 26.0\% [12], Jordan 15.2\% [13], and Uganda 19\% [14]. However, it was lower than the findings of South Africa 52\% [15]. This difference might be due to sociocultural differences and differences in implementation of health programs. The finding of this study is also consistent with study conducted in another part of the Ethiopia in Debra Berhan public health institution, 38.6\% [16].

The most common danger sign mentioned during pregnancy was vaginal bleeding at $64.7 \%$. This is greater than in Tsegedie district, Tigray 51.2\% [17]. The difference may be due to study period difference and increasing the number of staffs which providing counseling on danger signs during antenatal, childbirth and postnatal period. The finding of this study was comparable with the same study conducted in Debre berhan city administration 61.1\% [18]. Vaginal bleeding during childbirth was also mentioned by about $60 \%$ of the respondents, while persistent headache and blurred vision was mentioned by $24.9 \%$, which was higher than study conducted in aleta wendo district, sidama zone 55 and $7 \%$. The discrepancy may be due to improvement of service provision in maternity care [19]. In this study respondents who had a history of ANC were 1.26 times more knowledgeable than those who had no ANC visits. This finding is consistent with study done in other part of Ethiopia $[17,19]$. Simlarly in this study respondents who gave birth in health faclity was 3.57 times more likely to have good knowledge than those who gave birth at home.

\section{Conclusions}

This study's findings revealed that knowledge about obstetric danger signs of pregnancy overall was poor. The most commonly mentioned danger signs during pregnancy, and childbirth was severe vaginal bleeding followed by absence of fetal movements. From this study it can be concluded 
Table 3 knowledge of obstetric danger signs during pregnancy, child birth and postnatal among mothers in Shashamane town, April 2018

\begin{tabular}{ll}
\hline Variables $\quad$ Frequency $(n=422)$ & Percent $(\%)$ \\
\hline Danger sign during pregnancy &
\end{tabular}

Vaginal bleeding

$\begin{array}{ll}\text { Yes } & 273 \\ \text { No } & 149\end{array}$

Persistent nausea and vomiting

$\begin{array}{ll}\text { Yes } & 121 \\ \text { No } & 301\end{array}$

301

Swelling of body

$$
\text { Yes }
$$

No

298

29.4

70.6

Persistent headache and blurred vision

$$
\text { Yes } 164
$$$$
\text { No } 258
$$

Absent or decreased fetal movement

$\begin{array}{ll}\text { Yes } & 163 \\ \text { No } & 259\end{array}$

Severe abdominal cramps

$\begin{array}{ll}\text { Yes } & 121 \\ \text { No } & 301\end{array}$

Leakage of amniotic fluid without lab

Yes

No

303

High fever

$$
\text { Yes }
$$

No

324

Danger sign during child birth

Bleeding through birth canal

$\begin{array}{lll}\text { Yes } & 253 & 60 \\ \text { No } & 169 & 40\end{array}$

Persistent headache \&blurred vision

$$
\text { Yes } \quad 105
$$$$
\text { No } \quad 317
$$

swelling of hand, face etc.

$\begin{array}{ll}\text { Yes } & 54 \\ \text { No } & 368\end{array}$

Absent or decrease fetal movement

$$
\begin{array}{ll}
\text { Yes } & 120 \\
\text { No } & 302
\end{array}
$$

28.4

Increased blood pressure

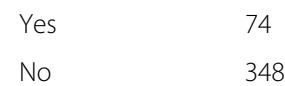

348

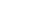

\section{4}

6

Table 3 knowledge of obstetric danger signs during pregnancy, child birth and postnatal among mothers in Shashamane town, April 2018 (Continued)

\begin{tabular}{ccc}
\hline Variables & Frequency $(n=422)$ & Percent (\%) \\
\hline Yes & 82 & 19.4 \\
No & 340 & 80.6 \\
Mal-presentation/position & \\
Yes & 54 & 12.8 \\
No & 368 & 87.2 \\
Severe continuous abdominal pain & \\
Yes & 120 & 28.4 \\
No & 302 & 71.6 \\
Danger sign during post-partum & \\
Post Natal Bleeding & & \\
Yes & 267 & 63.3 \\
No & 155 & 36.7 \\
Persistent headache $\&$ blurred vision & \\
Yes & 106 & 25.1 \\
No & 316 & 74.9 \\
Swelling hand, face & & 78.9 \\
Yes & 99 & 23.5 \\
No & 325 & 76.5 \\
Postnatal Fever & & \\
Yes & 168 & \\
No & 254 & \\
Yes & & \\
No & & \\
\hline
\end{tabular}

\footnotetext{
Retained Placenta (> 1 h.)
} 
Table 4 Factors associated with knowledge of key obstetric danger sign during pregnancy, child birth and postnatal period among mothers in Shashamane town, April 2018

\begin{tabular}{|c|c|c|c|c|}
\hline Types of variable & Good knowledge & Poor knowledge & COR $(95 \%$ C.I) & AOR (95\% C.I) \\
\hline \multicolumn{5}{|l|}{ Age of respondent } \\
\hline $15-19$ & 10 & 9 & 1 & 1 \\
\hline $20-24$ & 56 & 108 & $1.11(0.41-3.04)$ & $1.46(0.24-8.98)$ \\
\hline $25-29$ & 67 & 96 & $0.52(0.29-0.90)$ & $0.84(0.26-2.67)$ \\
\hline$\geq 30$ & 38 & 38 & $0.69(0.04-1.21)$ & $1.28(0.46-3.51)$ \\
\hline \multicolumn{5}{|l|}{ Occupation } \\
\hline House wife & 118 & 157 & 1 & 1 \\
\hline Governmental employed & 18 & 27 & $1.36(1.85-2.17)^{\mathrm{a}}$ & $2.05(0.97-4.32)$ \\
\hline Self-employed & 37 & 67 & $1.07(0.51-2.24)$ & $1.74(0.55-5.51)$ \\
\hline \multicolumn{5}{|l|}{ Number of pregnancy } \\
\hline 1 & 70 & 108 & 1 & 1 \\
\hline $2-5$ & 83 & 126 & $0.61(0.29-1.27)$ & $1.77(0.37-6.68)$ \\
\hline$\geq 6$ & 18 & 17 & $0.62(0.30-1.27)$ & $0.98(0.27-3.62)$ \\
\hline \multicolumn{5}{|l|}{ ANC follow up } \\
\hline No & 51 & 4 & 1 & 1 \\
\hline Yes & 120 & 247 & $0.67(0.45-1.54)$ & $1.26(1.07-1.85)^{a}$ \\
\hline \multicolumn{5}{|l|}{ Place of delivery } \\
\hline Home & 41 & 13 & 1 & \\
\hline Health center & 130 & 238 & $5.74\left(2.98 \_11.16\right)^{a}$ & $3.57(1.23-10.39)^{a}$ \\
\hline \multicolumn{5}{|l|}{ Source of information } \\
\hline Health personal & 32 & 204 & 1 & 1 \\
\hline Relative & 5 & 8 & $0.03(0.02-0.06)$ & $0.03(0.02-0.06)$ \\
\hline Friends & 2 & 10 & $0.14(0.04-0.45)$ & $0.28(0.05-0.17)$ \\
\hline Media & 123 & 29 & $0.04(0.09-0.21)$ & $0.05(0.01-0.31)$ \\
\hline \multicolumn{5}{|l|}{ Educational status } \\
\hline Informal education & 16 & 7 & 1 & 1 \\
\hline Formal education & 126 & 167 & $6.07(2.26-16.26)^{a}$ & $3.91(0.84-18.12)$ \\
\hline Collage and above & 29 & 77 & $2.03(1.23-3.25)^{a}$ & $1.96(0.95-4.05)$ \\
\hline \multicolumn{5}{|l|}{ Income } \\
\hline$<4000$ & 106 & 135 & 1 & 1 \\
\hline$>4000$ & 65 & 114 & $1.35(1.91-2.02)^{a}$ & $1.11(0.60-2.06)$ \\
\hline
\end{tabular}

that women's knowledge of danger signs during pregnancy and childbirth was increased by their educational level, number of ANC visits and having an institutional delivery. We recommended mobilizing communities to increase knowledge on obstetric danger sign during pregnancy. Similarly encouraging pregnant women to attend antenatal clinics and providing health information dissemination related to pregnancy danger sign and seeking behavior is also vital. Finally, we recommend further research to be conducted using both qualitative and quantitative methods to address the behavior and attitude of health care providers and maternity users regarding obstetric danger sign.

\section{Abbreviations}

ANC: Antenatal care; AOR: Adjusted odds ratio; Cl: Confidence interval; COR: Crude Odds ratio

Acknowledgements

We would like to express our deepest heartfelt thanks to Arba Minch University for allowing the conduct of this study. Our especial thanks also extended to data collectors and study participants.

\section{Authors' contributions}

$B W, A B, E H, H B, M M, B N$, TY and SB was involved in the conception, design, analysis, interpretation, report and manuscript writing. $S G, A B, A A, D U$ and BW were involved in the design, analysis, interpretation and report writing. All authors read and approved the final manuscript.

Funding

Not applicable. 


\section{Availability of data and materials}

The datasets used and/or analyzed during the current study available from the corresponding author on reasonable request.

\section{Ethics approval and consent to participate}

Ethical approval was obtained from the ethics committee of the Department of Midwifery, College of medicine Health Science, Arba Minch University. A letter from the research ethics committee was then submitted to the oromia Regional Health Bureau and the selected kebeles. After explaining the objectives of the study in detail, informed verbal consent was obtained from all study participants. All the participants were reassured of anonymity, as no personal identifiers were used. Then, after obtaining informed consent from every participant, the data collectors continued to show due respect to the norms, values, beliefs, and culture of the participants, and the confidentiality of the data was ensured.

\section{Consent for publication}

Not applicable.

\section{Competing interests}

The authors declare that they have no competing interests.

\section{Author details}

${ }^{1}$ Colleges of Medicine and Health Sciences, Arba Minch University, Arba

Minch, Ethiopia. ${ }^{2}$ Ethiopian Midwifery Association, Addis Ababa, Ethiopia.

Received: 19 October 2018 Accepted: 6 January 2020

Published online: 16 January 2020

\section{References}

1. Rashad WA, Essa RM. Women's awareness of danger signs of obstetrics complications in Egypt. J American Sci. 2010;6:1299-306.

2. Hiluf $M$, Fantahun M. Birth preparedness and complication readiness among women in Adigrat town, North Ethiopia. Ethiop J Health Dev. 2008;22:14-20.

3. Morsheda B, Hashima EN, Sarawat R. Stakeholders' knowledge in obstetric complications and role of health care providers in accessing emergency obstetric care: experiences from Nilphamari District, Bangladesh. Working paper no. 18; 2011. Available from: http://www.brac.net/research. Accessed 4 Apr 2012.

4. Sufiyan MB, Adam N, Umar AA, Ibrahim JM, Bashir SS, Birukila G. Knowledge, attitude and perception of pregnancy danger signs among women of childbearing age in samaru community northwestern Nigeria: results from a cross-sectional survey. Arch Med Surg. 2016;1(2):24

5. Kabakyenga JK, Ostergren PO, Turyakira E, Pettersson K. Knowledge of obstetric danger signs and birth preparedness practices among women in rural Uganda. BMC Pregnancy Child birth. 2011;11:73.

6. Nikiema B, Beninguisse G, Haggerty JL. Providing information on pregnancy complications during antenatal visits: unmet educational needs in subSaharan Africa. Health Policy Plan. 2009;34:370-4.

7. Agboola A. Text book of obstetrics and gynecology for medical student. 2nd ed. Ibadan: Heinemann Educational Books Plc; 2008. p. 305.

8. Federal Democratic Republic of Ethiopia, Ministry of Health. National reproductive strategy, 2006-2015. Addis Ababa: $\mathrm{FMOH}$; 2006. p. 16-21.

9. Policy Brief. Making pregnancy and childbirth safer. Washington, DC: USA World Population Reference Bureau; 1997. Available: www. measurecommunication.org

10. WHO. Why do so many women still die in pregnancy or childbirth? 2005.

11. WHO. Trends in maternal mortality: 1990 to 2010. Geneva: WHO, UNFPA, UNICEF and World Bank; 2012.

12. Rashad WA, Essa RM. Women's awareness of danger signs of obstetrics complications. J Am Sci. 2010;6(10):1299-306.

13. Okour A, Alkhateeb M, Amarin Z. Awareness of danger signs and symptoms of pregnancy complication among women in Jordan. Int J Gynecol Obstet. 2012;118(1):11-4.

14. Kabakyenga JK, Östergren P-O, Turyakira E, Pettersson KO. Knowledge of obstetric danger signs and birth preparedness practices among women in rural Uganda. Reprod Health. 2011;8(1):33.

15. Hoque $M$, Hoque M. Knowledge of danger signs for major obstetric complications among pregnant KwaZulu-Natal women: implications for health education. Asia Pac J Public Health. 2011;23(6):946-56.
16. Solomon AA, Amanta A, Chirkose E, Badi MB. Knowledge about danger signs of pregnancy and associated factors among pregnant women in Debra Birhan Town, Central Ethiopia. Sci J Public Health. 2015;3(2):269-73.

17. Hailu D, Berhe H. Knowledge about obstetric danger signs and associated factors among mothers in Tsegedie District, Tigray Region, Ethiopia; 2014.

18. Nurgi S. Knowledge attitude and practice of obstetrics danger sign during pregnancy in Debre Berhan Administration, Ethiopia; 2014.

19. Mesay $\mathrm{H}$, et al. Knowledge about obstetric danger signs among pregnant women in Aleta Wondo District, Sidama Zone, Southern Ethiopia. Ethiop Health Dev. 2007;20(1):25-32.

\section{Publisher's Note}

Springer Nature remains neutral with regard to jurisdictional claims in published maps and institutional affiliations.
Ready to submit your research? Choose BMC and benefit from:

- fast, convenient online submission

- thorough peer review by experienced researchers in your field

- rapid publication on acceptance

- support for research data, including large and complex data types

- gold Open Access which fosters wider collaboration and increased citations

- maximum visibility for your research: over $100 \mathrm{M}$ website views per year

At $\mathrm{BMC}$, research is always in progress.

Learn more biomedcentral.com/submissions 